Canadian

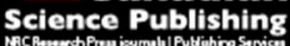

Applied Physiology, Nutrition, and Metabolism Physiologie appliquée, nutrition et métabolisme

\title{
POTENTIAL ERGOGENIC ACTIVITY OF GRAPE JUICE IN RUNNERS
}

\begin{tabular}{|r|l|}
\hline Journal: & Applied Physiology, Nutrition, and Metabolism \\
\hline Manuscript ID: & apnm-2015-0152.R2 \\
\hline Manuscript Type: & Article \\
\hline Date Submitted by the Author: & 23-Apr-2015 \\
\hline Complete List of Authors: & $\begin{array}{l}\text { Toscano, Lydiane; University Federal of Paraíba, Nutrition } \\
\text { Tavares, Renata; University Federal of Paraíba, Nutrition } \\
\text { Toscano, Luciana; University Federal of Paraíba, Nutrition } \\
\text { Silva, Cássia; University Federal of Paraíba, Nutrition } \\
\text { Almeida, Antônio; University Federal of Paraíba, Physical Education } \\
\text { Biasoto, Aline; Brazilian Agricultural Research Corporation, Semi-arid } \\
\text { Region } \\
\text { Golçalves, Maria da Conceiçao; University Federal of Paraiba, Nutrition } \\
\text { Silva, Alexandre; University Federal of Paraíba, Department of Physical } \\
\text { Education }\end{array}$ \\
\hline Keyword: & $\begin{array}{l}\text { inflammation, athlete performance, ergogenic aids < athlete performance, } \\
\text { sports nutrition < nutrition, stress < exercise }\end{array}$ \\
\hline
\end{tabular}




\section{POTENTIAL ERGOGENIC ACTIVITY OF GRAPE JUICE IN RUNNERS}

2 Lydiane Tavares Toscano, Renata Leite Tavares, Luciana Tavares Toscano, Cássia Surama

3 Oliveira da Silva, Antônio Eduardo Monteiro de Almeida, Aline Camarão Telles Biasoto,

4 Maria da Conceição Rodrigues Gonçalves, Alexandre Sérgio Silva

7 L.T. Toscano; R.L. Tavares; L.T. Toscano; C.S.O. Silva; M.C.R. Gonçalves. Department

8 of Nutrition, Federal University of Paraiba, CEP 58051-900, João Pessoa, Paraíba, Brazil.

9 Email: lyditavares@hotmail.com; renataltav@gmail.com; lucianatavares_3@hotmail.com; suramajpa2@hotmail.com; raulceica@ig.com.br

A.C.T. Biasoto. Brazilian Agricultural Research Corporation, Semi-arid Region (Embrapa Semi-arid), CEP 56302-970, Petrolina, Pernambuco, Brazil. Email: aline.biasoto@embrapa.br

A.E.M. de Almeida. Cardiologist, Department of Physical Education, Federal University of

Paraíba, CEP 58040-490, João Pessoa, Paraiba, Brazil. Email: aema.jp@gmail.com

Corresponding author: A.S. Silva. Department of Physical Education, Federal University of

Paraiba, João Pessoa, Paraiba, Brazil. Rua Silvino Lopes, 410/ apto 804, Tambaú - João

Pessoa/ Paraíba, Brasil, CEP 58039-190. E-mail: alexandresergiosilva@yahoo.com.br. Voice: +55 (83) 8875-4675. 


\section{Abstract}

Recent studies have indicated that certain food products have ergogenic potential similar to that of sports supplements. The present study aimed to investigate the potential ergogenic effect of integral purple grape juice on the performance of recreational runners. Twenty eight volunteers of both genders $\left(39.8 \pm 8.5\right.$ years; peak oxygen consumption [ $\left.\mathrm{VO}_{2 \text { peak }}\right]$ of $43.2 \pm$ $8.5 \mathrm{~mL} / \mathrm{kg} / \mathrm{min}$ ) were randomized into either a group that received grape juice (grape juice group - GJG, $\mathrm{n}=15 ; 10 \mathrm{~mL} / \mathrm{kg} / \mathrm{min}$ for 28 days) or a group that received an isocaloric, isoglycemic and isovolumetric control beverage (control group - $\mathrm{CG}, \mathrm{n}=13$ ). A time-toexhaustion exercise test, anaerobic threshold test and aerobic capacity test were performed, together with assessments of markers of oxidative stress, inflammation, immune response and muscle injury, performed at baseline and 48 hours after the supplementation protocol. The GJG showed a significant increase $(15.3 \%)$ in running time-to-exhaustion $(p=0.002)$ without significant improvements in either anaerobic threshold $(3.6 \% ; \mathrm{p}=0.511)$ or aerobic capacity $(2.2 \% ; p=0.605)$. In addition, GJG exhibited significant increases in total antioxidant capacity (38.7\%; $\mathrm{p}=0.009)$, vitamin $\mathrm{A}(11.8 \% ; \mathrm{p}=0.016)$ and uric acid $(28.2 \% ; \mathrm{p}=0.005)$, whereas alpha-1-acid glycoprotein significantly decreased $(20.2 \% ; \mathrm{p}=0.006)$ and high-sensitivity $\mathrm{C}$ reactive protein levels remained unchanged. In contrast, no significant changes occurred in any of these variables in the CG. Concluded that supplementation with purple grape juice shows an ergogenic effect in recreational runners by promoting increased time to exhaustion, accompanied by increased antioxidant activity and a possible reduction in inflammatory markers.

Keywords: polyphenols, functional food, antioxidant, oxidative stress, inflammation, athletic performance 


\section{Introduction}

In recent years several studies have reported ergogenic effects in athletes using raw or processed food products (Nieman et al. 2012; Samaras et al. 2014). In most cases, the observed ergogenic effects include decreases in oxidative stress and in the inflammatory process (Howatson et al. 2010; Miranda-Vilela et al. 2009; Tartibian and Maleki 2012).

Purple grapes and derivatives are recognized as food products with the highest antioxidant and anti-inflammatory activities (Dani et al. 2007). These properties have been demonstrated by their cardioprotective, neuroprotective, hepatoprotective and anticarcinogenic effects (Dani et al. 2008b; Georgiev et al. 2014; Toaldo et al. 2014), which are conferred by phenolic compounds, including anthocyanidins, catechins, quercetin and resveratrol, that possess high antioxidant and anti-inflammatory activities (Ali et al. 2010; Flamini et al. 2013). Among grape derivatives, the juice has received attention in recent years, with a worldwide production of approximately 12 million hectoliters (Lima et al. 2014).

Meanwhile, intense training can result in impaired redox balance and inflammation (Kreher and Schwartz 2012; Yaegaki et al. 2008). Considering the antioxidant and antiinflammatory potential of purple grapes and derivatives, it is plausible to hypothesize that purple grape juice may have an ergogenic effect in athletes, as has been demonstrated for other food products. In fact, previous studies using animal models have shown that grape derived products improve redox balance (Belviranli et al. 2012; Dalla Corte et al. 2013; Veskouski et al. 2012) and decrease muscle injury caused by intense training (Minegishi et al. 2011). In addition, physical performance was improved after the intake of red grape leaf extract (Minegishi et al. 2011), red wine (Dal-Ros et al. 2011), grape seed extract (Belviranli et al. 2012) and grape pomace extract (Veskoukis et al. 2012) in rats.

However, only a few studies have investigated these effects in humans. A single study reported increased antioxidant capacity and reduced muscle injury followed by improved 
muscle resistance and strength with the intake of grape extract in handball players (Lafay et al. 2009). Another study involving healthy non-athlete adults did not observe any improvements in peak oxygen consumption $\left(\mathrm{VO}_{2 \text { peak }}\right)$, time-to-exhaustion running and inflammation after the consumption of freeze-dried grapes (O'Connor et al. 2013). Similarly, Gonçalves et al. (2011) supplemented triathletes with organic grape juice (Vitis labruscaBordeaux), however what they observed were improvements in microvascular parameters, glucose homeostasis and antioxidant activity, which are markers associated to health and are not directly associated with the performance capacity in athletes. Therefore, studies on the ergogenic potential of grapes and derivatives in athletes are scarce, although some studies support the hypothesis that these effects may influence the physiological parameters involved in performance. In addition, each $V$. labrusca grapes variety presents a phenolic composition and bioactive properties peculiar. This evaluation and this profile are important to identification of nutritional content of beverages made from grape (Dani et al. 2007).

To explain this gap, the present study aimed to investigate the effects of integral purple grape juice supplementation on oxidative stress, inflammation, immune response and muscle injury and whether possible improvements in these variables would result in higher performance in recreational runners.

\section{Materials and methods}

\section{Subjects}

The study was conducted with men and women who train and participate in an amateur way rustic run without being top athletes, but in order to improve personal performance. Twenty eight runners were randomly (www.randomizer.org) distributed in two groups: 15 were assigned to a group receiving grape juice (grape juice group - GJG; $42.7 \pm$ 8.1 years, $11 \mathrm{men})$, and 13 were assigned to a control group (CG; $36.3 \pm 8.0$ years, $11 \mathrm{men})$. 
102 The sample size was calculated as proposed by Eng (2003), considering a increase in serum

103 antioxidant activity from $3.6 \pm 0.2 \mathrm{mmol} / \mathrm{L}$ to $3.9 \pm 0.4 \mathrm{mmol} / \mathrm{L}$ in response to integral purple

104 grape juice supplementation - concord grape, Vitis labrusca (O'Byrne et al. 2002). A

105 minimum of 13 subjects were assigned to each group, considering $\alpha$ error of 0.05 and

106 statistical power of 0.90 .

107 To participate of the study, volunteers should have at least one year of training with

108 frequency of five training sessions per week (at least three sessions should be running) at least

109 three months without interruption in the season and should be participating in competitions on

110 a regular basis. The participants should not have any chronic degenerative diseases, not be a

111 smoker and not make continued use of any medication. In addition, they should not have the

112 habit of consuming red wine or purple grape juice regularly, along with any dietary

113 supplements, vitamins or bioactive grape products (polyphenols). During the study athletes

114 with musculotendinous injuries, those who changed their usual eating or physical training

115 patterns, started drug therapy and those who did not consume the proper amounts of products

116 provided during the study period were excluded from the study.

117 The study was approved by the Research Ethics Committee of the Lauro Wanderley

118 University Hospital, Federal University of Paraiba under protocol nº 637299/14. The

119 participants signed an Informed Consent form according to Resolution 466/12 of the National

120 Health Council.

\section{Experimental design}

As shown in Figure 1, after 48 hours without training and a 12 hours fasting period,

the athletes were initially subjected to assessment of their nutritional and sleep status, blood 
127 protocol for 28 days. On the $14^{\text {th }}$ day and 48 hours after the $28^{\text {th }}$ day of supplementation the

128 volunteers were subjected to the same initial assessments, except for the performance tests, 129 which were conducted only at the beginning and end of the study.

130

131

132

133

134

135

136

137

138

139

140

141

142

143

144

145

146

147

148

149

150

\section{Nutritional assessment}

Dietary intake was assessed by 24-hours dietary recalls administered three times for each individual, being twice during the week and once during the weekend. The average dietary intake was used to calculate the intake of nutrients using Avanutri Revolution software, version 4.0 (Avanutri ${ }^{\circledR}$, Rio de Janeiro, Brazil). Body fat percent of was assessed according with protocol proposed by Jackson et al. (1980) for women and Jackson and Pollock (1978) for men, using a scientific plicometer (Cescorf, Porto Alegre, Brazil).

\section{Supplementation protocol}

The study used whole purple grape juice from Brazil (Casa de Bento, Bento

Gonçalves, Rio Grande do Sul) produced from grapes of the varieties Isabel, Bordeaux and Concord (Vitis labrusca). The quantification of juice phenolics was previously evaluated according to Rossi and Singleton (1965) to total phenolic compounds, to total monomeric anthocyanins using proposed by Lee et al. (2005) and antioxidant activity according to Brand-Williams et al. (1995).

The GJG consumed $10 \mathrm{~mL} / \mathrm{kg}$ /day of purple grape juice (O'Byrne et al. 2002) divided in doses prior to and immediately after training for 28 days. On the days without training the supplementation was consumed during meals. The $\mathrm{CG}$ received a carbohydrate based beverage (artificial grape flavor) with the same amount of calories, carbohydrates and volume as the grape juice, as proposed by McLeay et al. (2012) and Tsitsimpikou et al. (2013). 
152

153

154

155

156

157

\section{Anaerobic threshold and aerobic capacity}

In the week prior to and 24 hours after supplementation, the participants underwent a cardiopulmonary exercise test following the ramp protocol (Bruce et al. 1963) with incremental loads at every 3 minutes. Analysis of exhaled gases was performed using a Metalyzer 3B (Cortex, Leipzig, Germany) associated with an ErgoPC Elite computerized system (Micromed Biotecnologia ${ }^{\circ}$, Brasília, Brazil). A cardiologist performed the tests under controlled temperature and humidity. Peak functional capacity $\left(\mathrm{VO}_{2 \text { peak }}\right)$ and the point of respiratory compensation were considered indicative of the anaerobic threshold.

\section{Time-to-exhaustion running}

A time-to-exhaustion exercise test with constant speed, performed at the anaerobic threshold was conducted one week prior to the beginning of supplementation and at the end, always 48 hours after the cardiopulmonary exercise test. The test was performed on a treadmill (Movement LX 160 GII, São Paulo, Brazil) under controlled temperature and relative humidity. The test was interrupted when the runner exhibited an inability to follow the treadmill's speed in addition to verbal confirmation by the athlete and a reference between 19 and 20 on the Borg Rating of Perceived Exertion Scale (1982). The total run time was recorded.

\section{Oxidative stress}

Oxidative stress was measured through of the lipid peroxidation which was quantified by malondialdehyde (MDA) metabolic product. For this adopted the thiobarbituric acid reaction (TBARS) in the plasma according to method described by Ohkawa et al. (1979). In addition, total antioxidant capacity (TAC) was quantified in the plasma by measuring the 
176

scavenging activity of the free radical 2,2-diphenyl-1-picrylhydrazyl using the method described by Brand-Williams et al. (1995).

The serum levels of vitamins A and E were measured using high-performance liquid chromatography (Dionex Ultimate 3000; Thermo Scientific, Massachusetts, USA) at $325 \mathrm{~nm}$ for the quantification of vitamin A (retinol) and $295 \mathrm{~nm}$ for the quantification of vitamin $\mathrm{E}(\alpha-$ tocopherol).

The serum level of uric acid was measured by the Trinder's glucose oxidase method using a specific commercial kit (Labtest, Minas Gerais, Brazil) in an automated analyzer (LabMax 240 Premium; Labtest, Minas Gerais, Brazil) according to the manufacturer instructions.

\section{Inflammation}

The plasma concentrations of high-sensitivity C-reactive protein (hs-CRP) and alpha1-acid glycoprotein (AGP) were quantified by immunoturbidimetry using specific commercial kits (Labtest, Minas Gerais, Brazil) and an automatic analyzer (LabMax 240 Premium; Labtest, Minas Gerais, Brazil) according to the manufacturer instructions.

\section{Immune response}

Total leukocytes were quantified in EDTA whole blood samples and were differentiated into monocytes, lymphocytes, and neutrophils by electronic cell counting using an automated hematology analyzer (Cell Dyn 3500; Abbott, Wielkopolskie, Poland) according to the manufacturer instructions.

\section{Muscle injury}


The plasma level of creatine kinase (CK) was measured using catalytic activity method and concentrations of lactate dehydrogenase (LDH) using the pyruvate-lactate method, both with specific commercial kits (Labtest, Minas Gerais, Brazil) in an automated analyzer (LabMax 240 Premium; Labtest, Minas Gerais, Brazil) according to the manufacturer instructions.

\section{Statistical analysis}

Data are presented as means \pm standard deviations. Normality and homogeneity were evaluated using the Shapiro-Wilk test and Levene test respectively. Data were analyzed using Student t-test, one-way analysis of variance (ANOVA) or repeated measures ANOVA, with Tukey post-hoc test, as appropriate. Values of $\mathrm{p}<0.05$ were considered statistically significant. The software GraphPad Instat 3.0 (San Diego, CA, USA) was used.

\section{Results}

\section{Quantification of grape juice phenolics}

The polyphenols were quantified in grape juice and found 1.82 g. $\mathrm{L}^{-1}$ of the total phenolic compounds found $52.58 \mathrm{mg} . \mathrm{L}^{-1}$ of the total monomeric anthocyanins and found 1.16 $\mu \mathrm{Mol}$ EAG $\mathrm{mL}^{-1}$ of the antioxidant activity.

\section{Study group characterization}

The baseline characteristics of the groups are shown in Table 1. The aerobic capacity of these athletes was classified as good for health purposes (ACSM 2000). However, the capacity was rated as average for competitive purposes. Therefore, they were classified as recreational athletes. The results of the anaerobic threshold test and the time-to-exhaustion exercise test, in addition to most of the variables evaluated, including running experience, 
225

226

227

228

229

230

231

232

233

234

235

236

237

238

239

240

241

242

243

244

245

246

247

248

249

weekly training load and all physiological variables were similar between the groups.

However, the number of hours of sleep was different between the two groups and was higher in the CG. All athletes practiced running at least three times a week, complemented by other activities, including functional training, weight lifting or cycling.

\section{Nutritional assessement}

During the 28 days of study the GJG had an average consumption of $32.4 \pm 11.4$ $\mathrm{kcal} / \mathrm{kg} /$ day being $4.5 \pm 1.5 \mathrm{~g} / \mathrm{kg} /$ day carbohydrate, $1.4 \pm 0.5 \mathrm{~g} / \mathrm{kg} /$ day proteins and $1.0 \pm 0.5$ $\mathrm{g} / \mathrm{kg} /$ day lipids, while CG consumed $40.9 \pm 16.6 \mathrm{kcal} / \mathrm{kg} /$ day being $5.5 \pm 2.7 \mathrm{~g} / \mathrm{kg} / \mathrm{day}$ carbohydrate, $1.6 \pm 0.8 \mathrm{~g} / \mathrm{kg} /$ day proteins and $1.2 \pm 0.4 \mathrm{~g} / \mathrm{kg} /$ day lipids. This food consumption of the groups was similar with regard to the intake of calories and macronutrients, as well as for micronutrients coming from the diet. Considering the reference values proposed by the International Society of Sports Nutrition (Kreider et al. 2010), runners in both groups consumed a low-calorie diet. The GJG consumed a hypoglycemic diet, whereas the CG consumed a hyperlipidic diet. Both groups presented low intake of vitamins A and E, selenium and copper. During the intervention, the groups did not change their eating habits. In addition, body weight to GJG (67.9 \pm 12 vs $68.3 \pm 12 \mathrm{~kg}$; $\mathrm{p}=0.20)$ and to $\mathrm{CG}(77.5 \pm 14$ vs $77.0 \pm 14 \mathrm{~kg} ; \mathrm{p}=0.36$ ) did not change during the intervention period. Fat percentage to GJG $(21.2 \pm 7.8$ vs $21.0 \pm 8.1 ; p=0.25)$ and to $C G(20.0 \pm 9.1$ vs $20.6 \pm 8.9 ; p=0.24)$ also remained unchanged.

\section{Anaerobic threshold, aerobic capacity and time-to-exhaustion}

Supplementation with grape juice significantly increased the time-to-exhaustion running by $15.3 \%$ in the GJG, whereas the CG showed a small and no significant decrease of $2.2 \%$. The absolute values during pre- and post-supplementation are shown in Table 2 . The 
250 improved performance of the GJG was accompanied by a minor and no significant increase of $2513.6 \%$ in the anaerobic threshold, whereas CG showed a small and no significant decrease of $2521.6 \%$. The peak aerobic capacity did not change significantly after 28 days of 253 supplementation, with only a minor increase observed in both groups (table 2).

\section{Oxidative stress}

The MDA data indicated that grape juice supplementation did not prevent lipid peroxidation in athletes as shown in Figure 2. Similarly, the CG showed no significant differences between the pre- and post-intervention periods. In contrast, of the four variables associated with antioxidant activity, three variables were significantly improved with grape juice supplementation, which were not observed in the CG (Figure 3). The TAC in the GJG increased by $38 \%$ on the $28^{\text {th }}$ day, compared with the pre-intervention period (Figure 3, panel D), accompanied by a $12 \%$ increase in the serum levels of vitamin A (Figure 3, panel A). In addition, the serum levels of uric acid significantly increased by $23 \%$ on the $14^{\text {th }}$ day and remained at this level until the $28^{\text {th }}$ day, compared with the pre-intervention period (Figure 3 , panel C). The serum levels of vitamin E remained unchanged throughout the study period in both groups (Figure 3, panel B).

\section{Inflammation}

Grape juice supplementation promoted a marked decrease in the serum level of the inflammatory marker AGP to GJG by $13 \%$ on the $14^{\text {th }}$ day and by $20 \%$ on the $28^{\text {th }}$ day of supplementation, compared with the beginning of nutritional intervention (Figure 4, panel A). In contrast, hs-CRP levels remained unchanged in response to supplementation (Figure 4, panel B). The levels of all inflammatory markers remained unchanged in the CG during the study period. 


\section{Immune response and muscle injury}

Serum counts of leukocytes, monocytes, lymphocytes and neutrophils remained unchanged at post-intervention moment in both groups, as shown in Table 3. Similarly, the activity of enzymes involved in muscle damage (CK and LDH) remained unchanged at $14^{\text {th }}$ and $28^{\text {th }}$ days compared with the pre-intervention period in both groups as observed in Table 3.

\section{Discussion}

This study demonstrated that daily supplementation with purple grape juice at 10 $\mathrm{mL} / \mathrm{kg}$ for 28 days significantly improved performance in recreational runners, followed by increases in total antioxidant capacity, vitamin A and uric acid and a possible decrease in inflammation.

The varieties of grapes used in juice are widely produced in the country where this study was conducted, and therefore the most widely consumed by this population. The results of the composition of phenolic content found in our study were quite different from previous studies. While we found $1.82 \mathrm{~g} / \mathrm{L}$, Gonçalves et al. (2011) found $5.32 \mathrm{~g} / \mathrm{L}$. What accounts for this difference is that Gonçalves et al. (2011) analyzed the organic juice, while we evaluated the phenolic content of the integral juice. Corroborating this explanation, O'Byrne et al. (2002) also evaluated the integral juice and found different values, but much closer to our results $(0.56 \mathrm{~g} / \mathrm{L})$.

The main finding of this study was the capacity of grape juice to increase time-toexhaustion running. It should be noted that the magnitude of the increase in performance of up to $15 \%$ was much higher than previously reported for most food products tested. Other studies have reported an increase of $5 \%$ in the running speed of recreational athletes after the consumption of sugar beet (Murphy et al. 2012), a 24.9\% increase in time-to-exhaustion and a 
$30110 \%$ increase in $\mathrm{VO}_{2 \text { peak }}$ in recreational runners after the consumption of peppermint 302 (Meamarbashi and Rajabi 2013) and a 1.9\% increase in the speed of female runners after the

303

304

305

306

307

308

309

310

311

312 consumption of blackcurrant juice (Braakhuis et al. 2013). Therefore, our data suggest the inclusion of grape juice as a potential ergogenic food product for athletes.

The consistency of our data is enhanced by the specificity of the test used, time-toexhaustion, which is the determining variable for performance in street running. This protocol has been the one most used by researchers to evaluate specific performance in endurance runners (Lunn et al. 2012; Meamarbashi and Rajabi 2013; Peschek et al. 2014) and cyclists (Kalpana et al. 2013; Muggeridge et al. 2014; Pritchett and Pritchett 2012).

Interestingly, the improvement in performance in this particular test was not accompanied by a significant increase in anaerobic threshold. However, the improvement of $3.6 \%$ in this test in the GJG represents an estimated additional 160 meters traveled in a 30minute run, considering that runners can remain at their anaerobic threshold speed for approximately 30 minutes. In contrast, the CG showed a decrease of $1.6 \%$, which would correspond to 95 meters less for the same event. In terms of athletic performance, these data represent a large competitive "window" in the placement of athletes in a runner competition. Historically, the antioxidant effect has been attributed to the polyphenolic compounds present in grape juice (Lippi et al. 2010; Renaud and De Lorgeril 1992). However, our data suggest that the increase in TAC may have been aided by the increase in the serum levels of uric acid. Uric acid is a major antioxidant in plasma and functions as a scavenger of peroxyl and hydroxyl radicals (Fabbrini et al. 2014). These results corroborate to Gonçalves et al. (2011), who observed a 33\% increase in the serum levels of uric acid in male triathletes after ingestion of $300 \mathrm{~mL} /$ day of organic purple grape juice for 20 days. In this respect, the strong correlation observed between the levels of uric acid and the antioxidant activity in plasma was 
considered one of the beneficial effects of the consumption of apple juice in healthy adults (Godycki-Cwirko et al. 2010).

In addition, among the two antioxidant vitamins analyzed, only vitamin A significantly increased after supplementation. This result is corroborated by Choi et al. (2012), who reported significant increases in the levels of total vitamin A and retinol after grape seed extract supplementation in rats. The unchanged levels of vitamin $\mathrm{E}$ in our study corroborate the results of O'Byrne et al. (2002), who supplemented the same daily dose of grape juice for two weeks. In contrast, Lafay et al. (2009) reported that grape extract supplementation increased serum vitamin $\mathrm{E}$ levels in athletes.

Interestingly, AGP analysis indicated a significant reduction in systemic inflammation in athletes, whereas hs-CRP levels remained unchanged. Systemic inflammation has been considered as one of the most important physiological stress markers in athletes (Kreher and Schwartz 2012; Rogero et al. 2005; Smith 2000), considering that this process is involved in the etiology of overtraining (Carfagno and Hendrix 2014; Smith 2000). All of the studies conducted to date have used cytokines and hs-CRP as inflammatory markers. However, recent studies have considered AGP to be an effective marker of systemic inflammation, strongly associated with cytokines and a better diagnostic marker than hs-CRP because, although hsCRP has a faster response (1 to 2 days), AGP levels remain elevated for longer periods (5 to 6 days) (Ayoya et al. 2010; Fournier et al. 2000). Furthermore, AGP has been used as a diagnostic marker of systemic inflammation in cardiometabolic diseases (Piccirillo et al. 2004; Toscano et al. 2014).

These differences can be explained by the fact that hs-CRP levels decreased during the supplementation period. Therefore, the AGP behavior observed in the present study suggests a reduction in systemic inflammation in the athletes. Notwithstanding the above, the evaluation of pro- and anti-inflammatory cytokines is necessary to confirm these effects and it 
350

is prudent before to suggest the potential reduction in inflammation as the beneficial effect of grape juice supplementation in athletes.

While the findings related to the reduction of oxidative stress and inflammation can be explained similarly to previous studies in which these effects were found in cardiometabolic diseases (i.e. antioxidant and anti-inflammatory action of the polyphenols), the mechanisms by which grape juice promoted performance improvement are still not investigated. The most plausible explanation is that the improvement of redox state and inflammatory status can have contributed to better recovery between daily training sessions. But only daily analysis (pre and post exercises) assessing the acute responses to sessions training could confirm this possibility.

Taken together, this study showed that a supplementation protocol with grape juice for 28 days resulted in increased performance in the time-to-exhaustion test, followed by increased antioxidant activity and a possible reduction in systemic inflammation in recreational runners. Although Gonçalves et al. (2011) have tested the effect of grape juice in athletes, these authors evaluated only cardiometabolic parameters related to health but no one variables related to the performance was evaluated. So this is the first study in which the sports ergogenic effect is attributed to the full purple grape juice.

The practical implication of this study involves the indication of grape juice as a food product with ergogenic properties for recreational athletes. Therefore, grape juice is an attractive alternative for athletes seeking improved sports performance but who want to avoid the use of dietary supplements owing to the controversies on their efficacy and safety (Silva et al. 2014). This effect was detected with the use of $10 \mathrm{~mL} / \mathrm{kg} /$ day, which can be regarded as high compared to other studies with doses ranging from $100 \mathrm{~mL} /$ day to $480 \mathrm{~mL}$ / day (Castilla et al. 2006; Cho et al. 2015). For dose used in the study, five of the fifteen athletes reported mild gastrointestinal discomfort in the first, second or third day, however these symptoms 
375 disappeared after this period. Furthermore, no hepatic or renal events were detected, 376 according markers used in this study and no athlete complained of the doses administered. On 377 the other hand, the cost of full purple grape juice is high compared to other types of juices or 378 fruit so that the effectiveness of lower doses still deserves to be tested. The continued use of 379 the juice with lower doses deserves to be investigated with view to future proposals for 380 insertion of purple grape juice in the daily dietary habits of the athletes.

381 Future prospects include the performance of studies involving high-performance 382 athletes because the results presented herein are valid only for recreational athletes. In 383 addition, further studies on cytokines should be conducted to elucidate the anti-inflammatory 384 role of grape juice.

385 Acknowledgments

386 Purple grape juice composition was performed by Enology Laboratory of Embrapa Semi387 Arid, located in Petrolina, Pernambuco, Brazil.

\section{References}

390

Ali, K., Maltese, F., Choi, Y., and Verpoorte, R. 2010. Metabolic constituents of grapevine and grape-derived products. Phytochem. Rev. 9(3): 357-378. PMID:20835385

American College of Sports Medicine (ACSM) 2000. Guidelines for Graded Exercise Testing and Exercise Prescription. 6th ed. Philadelphia: Lippincott Williams and Wilkins, 300-312.

Ayoya, M.A., Spiekermann-Brouwer, G.M., Stoltzfus, R.J., Nemeth, E., Habicht, J.P., Ganz, 398 T., et al. 2010. Alpha-1-acid glycoprotein, hepcidin, C-reactive protein, and serum ferritin are 
399 correlated in anemic schoolchildren with Schistosoma haematobium1-3. Am. J. Clin. Nutr.

400 91(6): 1784-90. doi:10.3945/ajcn.2010.29353. PMID:20410090.

401

402 Belviranli, M., Gökbel, H., Gkudan, N., and Basarali, K. 2012. Effects of grape seed extract 403 supplementation on exercise-induced oxidative stress in rats. Br. J. Nutr. 108(2): 249-256. 404 doi:10.1017/S0007114511005496. PMID:22011589.

405

406 Bertolazi, A.N., Fagondes, S.C., Hoff, L.S., Pedro, V.D., Barreto, S.S.M., and Johns, M.W. 407 2009. Portuguese-language version of the Epworth sleepiness scale: validation for use in 408 Brazil. J. Bras. Pneumol. 35(9): 877-883. doi:10.1590/S1806-37132009000900009. 409 PMID:19820814. 410

Borg, G.A. 1982. Psychophysical bases of perceived exertion. Med. Sci. Sports Exerc. 14(5), 412 377-381. PMID:7154893.

413

414 Braakhuis, A. J., Hopkins, W. G., and Lowe, T. E. 2013. Effects of dietary antioxidants on 415 training and performance in female runners. Eur. J. Sport Sci. 14(2): 160-168.

416 doi:10.1080/17461391.2013.785597. PMID:23600891.

417

418 Brand-Williams, W., Cuvelier, M. E., and Berset, C. 1995. Use of a free radical method to 419 evaluate antioxidant activity. LWT - Food Sci. Technol. 28(1): 25-30. doi:10.1016/S0023$420 \quad 6438(95) 80008-5$.

421

422 Bruce, R.A., Blackman, J.R., Jones, J.W., and Strait, G. 1963. Exercising testing in adult 423 normal subjects and cardiac patients. Pediatrics, 32:742-756. PMID:14070531 
425 Carfagno, D.G., and Hendrix, J.C. 2014. Overtraining syndrome in the athlete: current clinical 426 practice. Curr Sports Med Rep. 13(1): 45-51. doi: 10.1249/JSR.0000000000000027. PMID: 42724412891.

428

429 Castilla, P., Echarri, R., Dávalos, A., Cerrato, F., Ortega, H., Teruel, J.L., et al. 2006. 430 Concentrated red grape juice exerts antioxidant, hypolipidemic, and antiinflammatory effects 431 in both hemodialysis patients and healthy subjects. Am. J. Clin. Nutr. 84(1): 252-62. PMID: 43216825703.

433

Cho, M.R., Han, J.H., Lee, H.J., Park, Y.K., and Kang, M.H. 2015. Purple grape juice 435 supplementation in smokers and antioxidant status according to different types of GST 436 437 polymorphisms. J. Clin. Biochem. Nutr. 56(1): 49-56. doi: 10.3164/jcbn.14-1. PMID: 25678751.

438

439

440

Choi, S.K., Zhang, X.H., and Seo, J.S. 2012. Suppression of oxidative stress by grape seed supplementation in rats. Nutr. Res. Pract. 6(1): 3-8. doi:10.4162/nrp.2012.6.1.3. PMID:22413034.

Dalla Corte, C.L., Carvalho, N.R., Amaral, G.P., Puntel, G.O., Silva, L.F., Retamoso, L.T., et al. 2013. Antioxidant effect of organic purple grape juice on exhaustive exercise. Appl.

445 Physiol. Nutr. Metab. 38(5): 558-565. doi:10.1139/apnm-2012-0230. PMID:23668765.

447 Dal-Ros, S., Zoll, J., Lang, A.L., Auger, C., Keller, N., Bronner, C., et al. 2011. Chronic 448 intake of red wine polyphenols by young rats prevents aging-induced endothelial dysfunction 
449 and decline in physical performance: role of NADPH oxidase. Biochem. Biophys. Res.

450 Commun. 404(2): 743-749. doi:10.1016/j.bbrc.2010.12.060. PMID:21167817.

451

452 Dani, C., Oliboni, L.S., Bonatto, D., Vanderlinde, R., Salvador, M., and Henriques, J.A. 2007.

453 Phenolic content and antioxidant activities of white and purple juices manufactured with

454 organically-produced grapes. Food Chem. Toxicol. 45(12): 2574-2580. PMID: 17683842.

455

456 Dani, C., Oliboni, L.S., Pasquali, M.A., Oliveira, M.R., Umezu, F.M., Salvador, M., et al.

457 2008b. Intake of purple grape juice as a hepatoprotective agent in Wistar rats. J. Med. Food.

458 11(1): 127-132. doi: 10.1089/jmf.2007.558. PMID: 18361748.

459

460 Eng, J. 2003. Sample size estimation: how many individuals should be studied?. Radiology, 461 227(2): 309-313. PMID: 12732691.

462

463

Fabbrini, E., Serafini, M., Colic, B.I., Hazen, S.L., and Klein, S. 2014. Effect of plasma uric 464 acid on antioxidant capacity, oxidative stress, and insulin sensitivity in obese subjects. Diabetes, 63(3): 976-981. doi:10.2337/db13-1396. PMID:24353177.

466

467 Flamini, R., Mattivi, F., De Rosso, M., Arapitsas, P., and Bavaresco, L. 2013. Advanced

468 knowledge of three important classes of grape phenolics: anthocyanins, stilbenes and

469 flavonols. Int. J. Mol. Sci. 14(10): 19651-1969. doi:10.3390/ijms141019651.

$470 \quad$ PMID:24084717.

471

472 Fournier, T., Medjoubi-N, N., and Porquet, D. 2000. Alpha-1-acid glycoprotein. Biochim.

473 Biophys. Acta, 1482(1-2): 157-171. PMID:11058758. 
475 Georgiev, V., Ananga, A., and Tsolova, V. 2014. Recent advances and uses of grape

476 flavonoids as nutraceuticals. Nutrients, 6(1):391-415. doi:10.3390/nu6010391.

477 PMID:24451310.

478

479 Godycki-Cwirko, M., Krol, M., Krol, B., Zwolinska, A., Kolodziejczyk, K., Kasielski, M., et 480 al. 2010. Uric acid but not apple polyphenols is responsible for the rise of plasma antioxidant 481 activity after apple juice consumption in healthy subjects. J. Am. Coll. Nutr. 29(4): 397-406. 482 PMID: 21041815.

483

484

Gonçalves, M.C., Bezerra, F.F., Eleutherio, E.C., Bouskela, E., and Koury, J. 2011. Organic grape juice intake improves functional capillary density and postocclusive reactive hyperemia in triathletes. Clinics, 66(9): 1537-1541. PMID: 22179155.

487

488

Howatson, G., Mchugh, M.P., Hill, J.A., Brouner, J., Jewell, A.P., and Van Someren, K.A. 489 2010. Influence of tart cherry juice on indices of recovery following marathon running.

490

Scand. J. Med. Sci. Sports, 20(6): 843-852. doi:10.1111/j.1600-0838.2009.01005.x.

491

PMID:19883392.

492

493

494

Jackson, A.S., and Pollock, M.L. 1978. Generalized equations for predicting body density of men. Br. J. Nutr. 40(3): 497-504. PMID: 718832.

495

496 Jackson, A.S., Pollock, M.L., and Ward, A. 1980. Generalized equations for predicting body

497 density of women. Med. Sci. Sports Exerc.12(3): 175-181. PMID: 7402053. 
499 Kalpana, K., Lal, P.R., Kusuma, D.L., and Khanna, G.L. 2013. The effects of ingestion of 500 sugarcane juice and commercial sports drinks on cycling performance of athletes in 501 comparison to plain water. Asian J. Sports Med. 4(3): 181-189. PMID: 24427476

502

503 Kreher, J.B., and Schwartz, J.B. 2012. Overtraining syndrome: a practical guide. Sports 504 Health, 4(2): 128-138. PMID: 23016079.

505

506 Kreider, R. B., Wilborn, C.D., Taylor, L., Campbell, B., Almada, A.L., Collins, R. et al. 2010. 507 ISSN exercise and sport nutrition review: research and recommendations. J. Int. Soc. Sports 508 Nutr. 7(7): 1-43. doi:10.1186/1550-2783-7-7. PMID:20181066.

509

510 Lafay, S., Jan, C., Nardon, K., Lemaire, B., Ibarra, A., Roller, M., et al. 2009. Grape extract 511 improves antioxidant status and physical performance in elite male athletes. J. Sports Sci. 512 Med. 8(3): 468-480. PMID: 24150013

513

514 Lee, J., Durst., R.W., and Wrolstad, R.E. 2005. Determination of total monomeric 515 anthocyanin pigment content of fruit juices, beverages, natural colorants, and wines by the $\mathrm{pH}$ 516 differential method: Collaborative Study. J. AOAC Int. 88(5): 1269-1278. PMID: 16385975

518 Lima, M.S., Silani, I.S., Toaldo, I.M., Corrêa, L.C., Biasoto, A.C., Pereira, G.E., et al. 2014. 519 Phenolic compounds, organic acids and antioxidant activity of grape juices produced from 520 new Brazilian varieties planted in the Northeast Region of Brazil. Food Chem. 161: 94-103. 521 doi:10.1016/j.foodchem.2014.03.109. PMID:24837926

522 
523

524

525

526

527

528

529

530

531

532

533

534

535

536

537

538

539

540

541

542

543

544

545

546

547

Lippi, G., Franchini, M., Favaloro, E.J., and Targher, G. 2010. Moderate red wine

consumption and cardiovascular disease risk: beyond the "French paradox". Semin. Thromb.

Hemost. 36(1): 59-70. doi: 10.1055/s-0030-1248725. PMID: 20391297

Lunn, W.R., Pasiakos, S.M., Colletto, M.R., Karfonta, K.E., Carbone, J.W., Anderson, J.M. et al. 2012. Chocolate milk and endurance exercise recovery: protein balance, glycogen, and performance. Med. Sci. Sports Exerc. 44(4):682-91. doi:10.1249/MSS.0b013e3182364162.

PMID: 21904247

McLeay,Y., Barnes, M.J., Mundel, T., Hurst, S.M., Hurst, R.D., and Stannard, S.R. 2012.

Effect of New Zealand blueberry consumption on recovery from eccentric exercise-induced muscle damage. J. Int. Soc. Sports Nutr. 9(1): 19-32. doi:10.1186/1550-2783-9-19.

PMID:22564864.

Meamarbashi, A., and Rajabi, A. 2013. The effects of peppermint on exercise performance. J. Int. Soc. Sports Nutr. 10(1): 15-21. doi:10.1186/1550-2783-10-15. PMID:23517650.

Minegishi, Y., Haramizu, S., Hase, T., and Murase, T. 2011. Red grape leaf extract improves endurance capacity by facilitating fatty acid utilization in skeletal muscle in mice. Eur. J. Appl. Physiol. 111(9): 1983-1989. doi:10.1007/s00421-011-1826-2. PMID:21249390.

Miranda-Vilela, A.L., Pereira, L.C., Gonçalves, C.A., and Grisolia, C.K. 2009. Pequi fruit (Caryocar brasiliense Camb.) pulp oil reduces exercise-induced inflammatory markers and blood pressure of male and female runners. Nutr. Res. 29(12): 850-858.

doi:10.1016/j.nutres.2009.10.022. PMID:19963158. 
549 Muggeridge, D.J., Howe, C.C., Spendiff, O., Pedlar, C., James, P.E., and Easton, C. A. 2014.

550 A single dose of beetroot juice enhances cycling performance in simulated altitude. Med. Sci.

551 Sports Exerc. 46(1): 143-150. doi:10.1249/MSS.0b013e3182a1dc51. PMID:23846159

552

553 Murphy, M., Eliot, K., Heuertz, R.M., and Weiss, E. 2012. Whole beetroot consumption

554 acutely improves running performance. J. Acad. Nutr. Diet. 112(4): 548-552. doi:

$555 \quad$ 10.1016/j.jand.2011.12.002. PMID: 22709704

556

557 Nieman, D. C., Gillitt, N.D., Henson, D. A., Sha, W., Shanely, R. A., Knab, A.M. et al. 2012.

558 Bananas as an energy source during exercise: a metabolomics approach. PLoS ONE, 7(5):

559 e37479. doi: 10.1371/journal.pone.0037479. PMID: 22616015.

560

561 O’Byrne, D.J., Devaraj, S., Grundy, S.M., and Jialal, I. 2002. Comparison of the antioxidant

562 effects of Concord grape juice flavonoids and $\alpha$-tocopherol on markers of oxidative stress in

563 healthy adults. Am. J. Clin. Nutr. 76(6): 1367-1374. PMID:12450905.

564

565 O'connor, P.J., Caravalho, A.L., Freese, E.C., and Cureton, K.J. 2013. Grape consumption's

566 effects on fitness, muscle injury, mood, and perceived health. Int. J. Sport Nutr. Exerc. Metab.

567 23(1): 57-64. PMID:22952194.

568

569 Ohkawa, H., Ohishi, N., and Yagi, K. 1979. Assay for lipid peroxides in animal tissues by

570 thiobarbituric acid reaction. Anal. Biochem. 95(2): 351-358. doi:10.1016/0003-

571 2697(79)90738-3. PMID:36810

572 
573 Peschek, K., Pritchett, R., Bergman, E., and Pritchett, K. 2014. The effects of acute post

574 exercise consumption of two cocoa-based beverages with varying flavanol content on indices

575 of muscle recovery following downhill treadmill running. Nutrients, 6(1): 50-62.

576 doi:10.3390/nu6010050. PMID:24362706.

577

578 Piccirillo, L.J., Gonçalves, M.F., Clemente, E.L., and Gomes, M.B. 2004. Markers of 579 inflammation in type 1 diabetic patients. Arq. Bras. Endocrinol. Metabol. 48(2): 253-260. 580 doi:10.1590/S0004-27302004000200008. PMID:15640880.

581

582

Pritchett, K., and Pritchett, R. 2012. Chocolate milk: a post-exercise recovery beverage for 583 endurance sports. Med. Sport Sci. 59:127-134. doi:10.1159/000341954. PMID:23075563.

584

Renaud, S., and De Lorgeril, M. 1992. Wine, alcohol, platelets, and the French paradox for 586 coronary heart disease. Lancet, 339(8808): 1523-1526. PMID:1351198.

587

Rogero, M. M., Mendes, R. M., and Tirapegui, J. 2005. Neuroendocrine and nutritional

589 aspects of overtraining. Arq. Bras. Endocrinol. Metab. 49(3): 359-368. doi:10.1590/S0004-

590 27302005000300006.

591

592 Rossi, J.A., and Singleton,V.L. 1965. Colorimetry of total phenolics winth 593 phosphomolybdicphosphotungstic acid reagents. Am. J. Enol. Vitic. 16(3): 144-158. 594

595 Samaras, A., Tsarouhas, K., Paschalidis, E., Giamouzis, G., Triposkiadis, F., Tsitsimpikou, 596 C., et al. 2014. Effect of a special carbohydrate-protein bar and tomato juice supplementation 
597 on oxidative stress markers and vascular endothelial dynamics in ultra-marathon runners.

598 Food Chem. Toxicol. 69: 231-236. doi:10.1016/j.fct.2014.03.029. PMID:24705018.

599

600 Silva, A., Santhiago, V., and Gobatto, C. 2006. Understanding the overtraining in sport: the 601 definition to treatment. Rev. Port. Ciên. Desp. 6(2): 229-238

602

Silva, W.V., Silva, M.I.A.G., Toscano, L.T., Oliveira, K.H.D., Lacerda, L.M., and Silva, A.S. 604 2014. Supplementation prevalence and adverse effects in physical exercise practitioners. Nutr. 605 Hosp. 29(1): 158-165. doi:10.3305/nh.2014.29.1.6853. PMID:24483975.

606

Smith, L.L. 2000. Cytokine hypothesis of overtraining: a physiological adaptation to excessive stress?. Med. Sci. Sports. Exerc. 32(2): 317-331. PMID:10694113.

609

610 Tartibian, B., and Maleki, B.H. 2012. The effects of honey supplementation on seminal 611 plasma cytokines, oxidative stress biomarkers, and antioxidants during 8 weeks of intensive 612 cycling training. J. Androl. 33(3): 449-461. doi:10.2164/jandrol.110.012815. PMID:21636735.

614

Toaldo, I. A., Cruz, F.A., Alves, T,L., Gois J.S., Borges, D.L.G., Cunha, E.P., et al. 2015.

616 Bioactive potential of Vitis labrusca L. grape juices from the Southern Region of Brazil:

617 Phenolic and elemental composition and effect on lipid peroxidation in healthy subjects. Food 618 Chem. 173: 527-535. doi: 10.1016/j.foodchem.2014.09.171. PMID: 25466055 
620 Toscano, L.T., Silva, C.S., Toscano, L.T., Almeida, A.E., Santos, A.C., and Silva, A.S. 2014.

621 Chia flour supplementation reduces blood pressure in hypertensive subjects. Plant Foods

622 Hum. Nutr. 69(4): 392-398. doi:10.1007/s11130-014-0452-7. PMID:25403867.

623

624 Tsitsimpikou, C., Kioukia-Fougia, N., Tsarouhas, K., Stamatopoulos, P., Rentoukas, E.,

625 Koudounakos, A., et al. 2013. Administration of tomato juice ameliorates lactate

626 dehydrogenase and creatinine kinase responses to anaerobic training. Food Chem. Toxicol.

627 61: 9-13. doi:10.1016/j.fct.2012.12.023. PMID:23291317.

628

629

Veskoukis, A.S., Kyparos, A., Nikolaidis, M.G., Stagos, D., Aligiannis, N., Halabalaki, M., et

630

al. 2012. The antioxidant effects of a polyphenol-rich grape pomace extract in vitro do not

631 correspond in vivo using exercise as an oxidant stimulus. Oxid. Med. Cell. Longev. 2012:

632 185867. doi:10.1155/2012/185867. PMID:22693650.

633

634

Yaegaki, M., Umeda, T., Takahashi, I., Yamamoto, Y., Kojima, A., and Tanabe, M. 2008.

635 Measuring neutrophil functions might be a good predictive marker of overtraining in athletes.

636 Luminescence, 23(5): 281-286. doi:10.1002/bio.1028. PMID:18452137

637

638

639

640

641

642

643

644 


\section{List of captions of the figure}

646

647

648 Figure 1. Design of the experimental study

649

650 Figure 2. Effects of red grape juice on serum concentrations of MDA. Data are expressed as 651 the mean \pm SD. * indicates a difference $(\mathrm{p}<0.05)$ in relation to the 14 th day; \# indicates a 652 difference $(\mathrm{p}<0.05)$ in relation to baseline (repeated measures ANOVA and one-way 653 ANOVA).

654

655

656

657

658 (repeated measures ANOVA and one-way ANOVA).

659

660 Figure 4. Effects of red grape juice on serum concentrations of proteins AGP and hs-CRP.

661 Data are expressed as the mean \pm SD. * indicates a difference $(\mathrm{p}<0.05)$ in relation to the 14 th 662 day; \# indicates a difference $(\mathrm{p}<0.05)$ in relation to baseline (repeated measures ANOVA and 663 one-way ANOVA). 
Table 1 - Baseline characteristics of the groups.

\begin{tabular}{|c|c|c|c|}
\hline & $\begin{array}{c}\text { Grape Juice } \\
(\mathrm{n}=15)\end{array}$ & $\begin{array}{c}\text { Control } \\
(n=13)\end{array}$ & $\mathbf{P}$ \\
\hline Age (years) & $42.7 \pm 8.1$ & $36.3 \pm 8.0$ & 0.05 \\
\hline Gender $(\mathrm{M} / \mathrm{F})$ & $11 / 04$ & $11 / 02$ & \\
\hline BMI $\left(\mathrm{kg} / \mathrm{m}^{2}\right)$ & $24.1 \pm 3.8$ & $25.3 \pm 3.4$ & 0.40 \\
\hline Body Fat (\%) & $21.0 \pm 7.7$ & $20.3 \pm 9.2$ & 0.72 \\
\hline RHR (bpm) & $57.1 \pm 8.3$ & $59.5 \pm 7.8$ & 0.50 \\
\hline $\mathrm{VO}_{2 \text { peak }}(\mathrm{mL} / \mathrm{kg} / \mathrm{min})$ & $45.0 \pm 8.1$ & $48.8 \pm 10.0$ & 0.43 \\
\hline TAn $(\mathrm{km} / \mathrm{h})$ & $10.6 \pm 2.3$ & $11.8 \pm 2.1$ & 0.32 \\
\hline Exhaustion time (minutes) & $89.1 \pm 49.9$ & $69.0 \pm 34.0$ & 0.34 \\
\hline Training (years) & $7.4 \pm 7.8$ & $4.5 \pm 4.8$ & 0.28 \\
\hline Training frequency (day/weeks) & $4.4 \pm 0.9$ & $4.3 \pm 1.1$ & 0.79 \\
\hline Training time (minutes/session) & $77.9 \pm 23.9$ & $78.3 \pm 38.1$ & 0.96 \\
\hline Training volume (km/weeks) & $48.1 \pm 16.8$ & $52.5 \pm 35.2$ & 0.67 \\
\hline $\begin{array}{l}\text { Complementary activity } \\
\text { (minutes/weeks) }\end{array}$ & $167.3 \pm 76.6$ & $191.4 \pm 87.8$ & 0.54 \\
\hline Work (hours/day) & $7.1 \pm 2.8$ & $8.9 \pm 3.3$ & 0.13 \\
\hline Sleep (hours/weeks) & $7.5 \pm 1.4$ & $8.8 \pm 1.2$ & $0.01 *$ \\
\hline ESS-BR & $4.4 \pm 2.5$ & $4.3 \pm 3.2$ & 0.98 \\
\hline $\operatorname{MDA}(\mu \mathrm{M})$ & $3.8 \pm 1.3$ & $4.3 \pm 1.0$ & 0.79 \\
\hline TAC (\%) & $22.5 \pm 5.5$ & $24.5 \pm 7.9$ & 0.48 \\
\hline Vitamin $\mathrm{A}(\mu \mathrm{g} / \mathrm{dL})$ & $35.5 \pm 3.2$ & $34.5 \pm 4.8$ & 0.64 \\
\hline Vitamin $\mathrm{E}(\mu \mathrm{g} / \mathrm{dL})$ & $10.3 \pm 1.6$ & $8.4 \pm 1.7$ & 0.05 \\
\hline Uric acid $(\mathrm{mg} / \mathrm{dL})$ & $3.9 \pm 1.6$ & $4.4 \pm 1.5$ & 0.45 \\
\hline hs-CRP (mg/dL) & $1.83 \pm 1.0$ & $1.61 \pm 0.9$ & 0.58 \\
\hline AGP (mg/dL) & $77.2 \pm 17.5$ & $64.9 \pm 15.8$ & 0.07 \\
\hline Leukocytes $\left(\mathrm{mm}^{3}\right)$ & $5813 \pm 711$ & $5475 \pm 619$ & 0.24 \\
\hline Monocytes $\left(\mathrm{mm}^{3}\right)$ & $324 \pm 78$ & $316 \pm 62$ & 0.80 \\
\hline Lymphocytes $\left(\mathrm{mm}^{3}\right)$ & $1950 \pm 454$ & $1804 \pm 685$ & 0.54 \\
\hline Neutrophils $\left(\mathrm{mm}^{3}\right)$ & $3254 \pm 828$ & $3254 \pm 511$ & 0.99 \\
\hline CK (U/L) & $133 \pm 93$ & $136 \pm 74$ & 0.93 \\
\hline LDH (U/L) & $203 \pm 56$ & $250 \pm 92$ & 0.14 \\
\hline
\end{tabular}

Data are expressed as the mean \pm SD. BMI - body mass index; RHR - resting heart rate; TAn - Anaerobic Threshold; ESS-BR - Epworth Sleepiness Scale - Brazil (Bertolazi et al. 2010); MDA - malondialdehyde; TAC - total antioxidant capacity; hs-CRP - high-sensitivity C-Reactive Protein; AGP $-\alpha_{1}$-Acid glycoprotein; CK creatine kinase; $\mathrm{LDH}-$ lactate dehydrogenase. ${ }^{*}$ indicates a difference $(\mathrm{p}<0.05)$ when comparing the groups using unpaired $t$ test. 
Table 2 - Effects of red grape juice on physical performance tests.

\begin{tabular}{cccc}
\hline & Initial & 28 days & $\Delta$ percentage $(\%)$ \\
\hline $\begin{array}{l}\text { Exhaustion test (min) } \\
\text { GJG }\end{array}$ & $89.1 \pm 49.9$ & $101.9 \pm 56.0^{\#}$ & $\uparrow 15.3 \pm 9.2$ \\
$\mathrm{CG}$ & $69.0 \pm 34.0$ & $68.2 \pm 33.2$ & $\downarrow 2.2 \pm 23.9$ \\
$\begin{array}{l}\text { Anaerobic Threshold } \\
(\mathrm{km} / \mathrm{h})\end{array}$ & & & \\
$\mathrm{GJG}$ & $10.6 \pm 2.3$ & $11.0 \pm 2.4$ & $\uparrow 3.6 \pm 14.6$ \\
$\mathrm{CG}$ & $11.8 \pm 2.1$ & $11.6 \pm 2.8$ & $\downarrow 1.6 \pm 19.6$ \\
$\mathrm{VO} 2$ peak $(\mathrm{mL} / \mathrm{kg} / \mathrm{min})$ & & & $\uparrow 2.2 \pm 11.9$ \\
$\mathrm{GJG}$ & $45.0 \pm 8.1$ & $45.9 \pm 8.8$ & $\uparrow 2.3 \pm 9.0$ \\
$\mathrm{CG}$ & $48.8 \pm 10.0$ & $49.9 \pm 10.9$ &
\end{tabular}

Data are expressed as the mean \pm SD. \# indicates a difference $(\mathrm{p}<0.05)$ compared to baseline values (paired $t$ test and unpaired $t$ test). 
Table 3 - Effects of red grape juice on immunocompetence markers and muscle damage enzymes.

\begin{tabular}{|c|c|c|c|c|}
\hline & Initial & 14 days & 28 days & $\mathbf{P}$ \\
\hline \multicolumn{5}{|c|}{ Leukocytes $\left(\mathrm{mm}^{3}\right)$} \\
\hline GJG & $5813 \pm 711$ & - & $6025 \pm 1080$ & 0.50 \\
\hline $\mathrm{CG}$ & $5475 \pm 619$ & - & $5295 \pm 1207$ & 0.65 \\
\hline \multicolumn{5}{|c|}{ Monocytes $\left(\mathrm{mm}^{3}\right)$} \\
\hline GJG & $324 \pm 78$ & - & $319 \pm 70$ & 0.84 \\
\hline $\mathrm{CG}$ & $316 \pm 62$ & - & $310 \pm 69$ & 0.72 \\
\hline \multicolumn{5}{|c|}{ Lymphocytes $\left(\mathrm{mm}^{3}\right)$} \\
\hline GJG & $1950 \pm 454$ & - & $1956 \pm 423$ & 0.95 \\
\hline $\mathrm{CG}$ & $1804 \pm 685$ & - & $1763 \pm 585$ & 0.74 \\
\hline \multicolumn{5}{|c|}{ Neutrophils $\left(\mathrm{mm}^{3}\right)$} \\
\hline GJG & $3254 \pm 828$ & - & $3436 \pm 843$ & 0.51 \\
\hline $\mathrm{CG}$ & $3254 \pm 511$ & - & $2963 \pm 894$ & 0.44 \\
\hline \multicolumn{5}{|l|}{$\mathrm{CK}(\mathrm{U} / \mathrm{L})$} \\
\hline GJG & $133 \pm 93$ & $125 \pm 74$ & $148 \pm 93$ & 0.53 \\
\hline $\mathrm{CG}$ & $136 \pm 74$ & $153 \pm 71$ & $196 \pm 120$ & 0.11 \\
\hline \multicolumn{5}{|l|}{ LDH (U/L) } \\
\hline GJG & $203 \pm 56$ & $213 \pm 69$ & $260 \pm 138$ & 0.14 \\
\hline $\mathrm{CG}$ & $250 \pm 92$ & $255 \pm 53$ & $277 \pm 75$ & 0.46 \\
\hline
\end{tabular}

Data are expressed as the mean $\pm \mathrm{SD}$. Data were tested using repeated measures ANOVA, one-way ANOVA and dependent $t$ test; $p<0.05$ indicates a significant difference. 




Figure 1. Design of the experimental study $95 \times 40 \mathrm{~mm}(300 \times 300$ DPI $)$ 


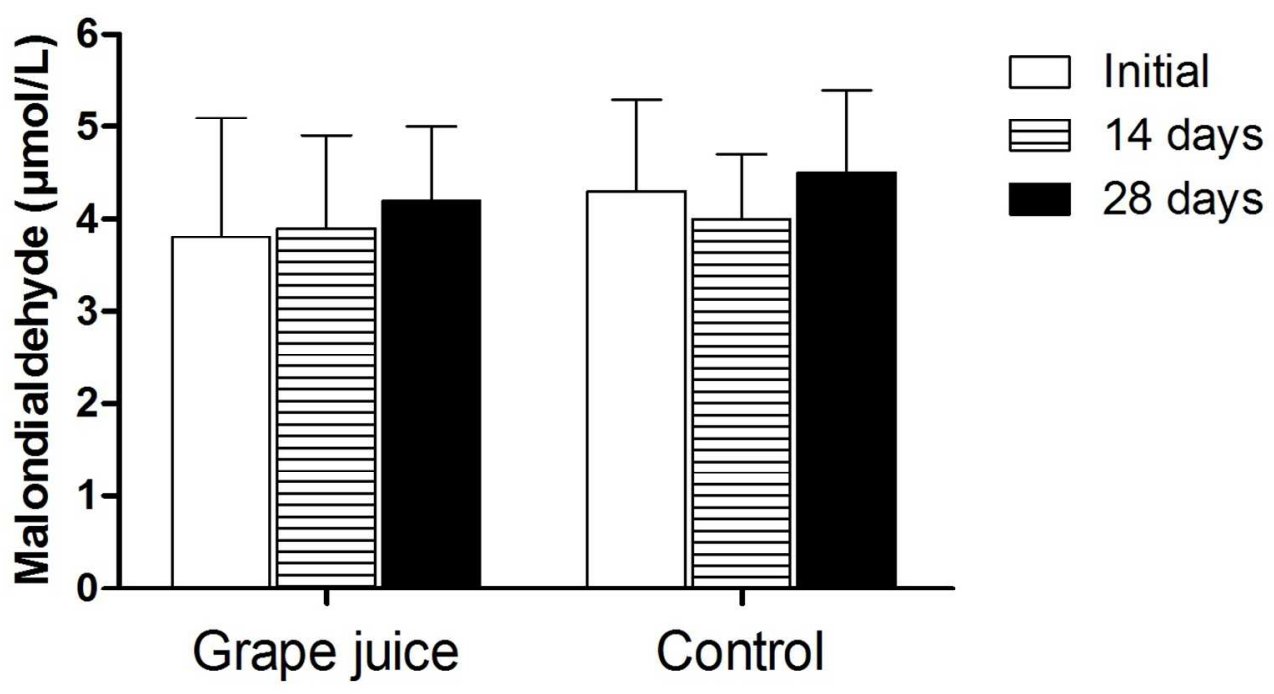

Figure 2. Effects of red grape juice on serum concentrations of MDA. Data are expressed as the mean \pm SD. * indicates a difference $(p<0.05)$ in relation to the 14 th day; \# indicates a difference $(p<0.05)$ in relation to baseline (repeated measures ANOVA and one-way ANOVA).

$119 \times 64 \mathrm{~mm}(300 \times 300 \mathrm{DPI})$ 



Figure 3. Effects of red grape juice on serum concentrations of vitamins $A$ and $E$, uric acid and total antioxidant capacity. Data are expressed as the mean \pm SD. * indicates a difference $(p<0.05)$ in relation to the 14th day; \# indicates a difference $(p<0.05)$ in relation to baseline (repeated measures ANOVA and oneway ANOVA). $222 \times 174 \mathrm{~mm}(300 \times 300 \mathrm{DPI})$ 

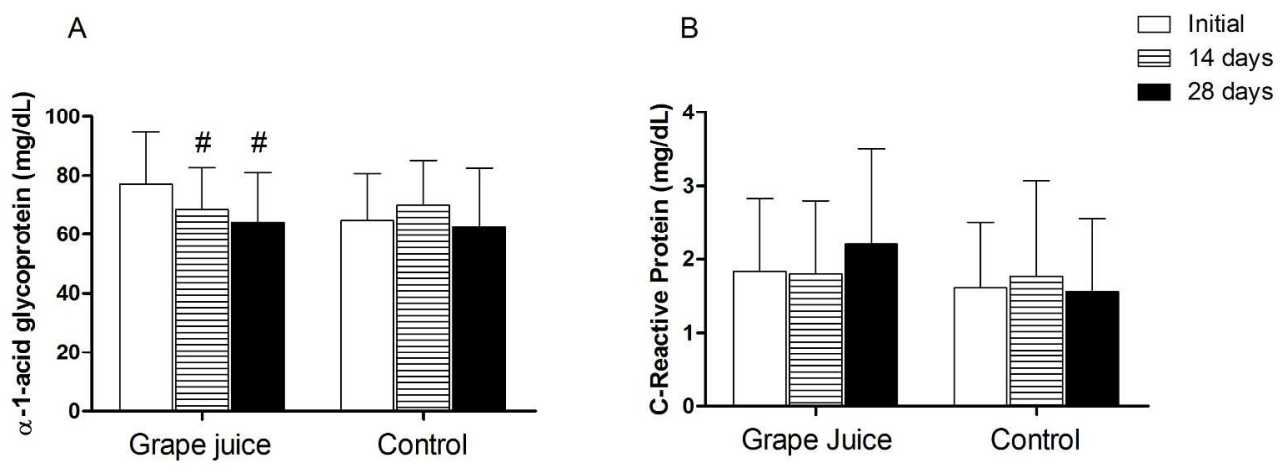

Figure 4. Effects of red grape juice on serum concentrations of proteins AGP and hs-CRP. Data are expressed as the mean $\pm S D$. * indicates a difference $(p<0.05)$ in relation to the 14 th day; \# indicates a difference $(p<0.05)$ in relation to baseline (repeated measures ANOVA and one-way ANOVA). $222 \times 82 \mathrm{~mm}(300 \times 300 \mathrm{DPI})$ 